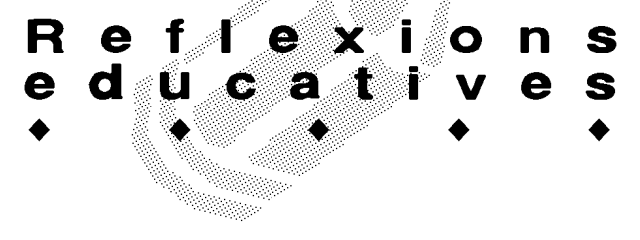

\title{
MODELS REACTIUS I APRENENTATGE
}

\author{
M. Carmen Pérez Ramírez. Àrea de Didàctica de l'Expressió Corporal. URV
}

Quantes vegades no ens hem sentit com extraterrestres amb els nostres comportaments, o bé hem pensat que la persona que teníem al davant ho era? Em refereixo al fet que a vegades no entenem com es poden donar conductes que se'ns escapen de les nostres coordenades i no sabem situar-les en el nostre sistema de comprensió. Fins i tot, ho veiem entre membres de la mateixa família, on es poden observar comportaments i manifestacions tan diferents entre uns i altres.

\section{Descobriment dels models reactius}

Aquest interrogant que em plantejava va anar aclarint-se fa quatre anys, quan per primera vegada vaig sentir parlar dels models reactius. No recordo quin títol tenia la xerrada, però em va atreure; potser ara és el menys important, però renoi, que interessant... va ser força enriquidora per a mi. Sobretot vaig veure la importància que tenien aquests models a l'hora d'entendre com es produeixen els aprenentatges.

El Dr. Mombiela, que era qui la impartia, va fer una explicació de gairebé dues hores, que van passar en un tres i no res. Aquest doctor té la capacitat de fer fàcil la comprensió de temes com ara el cervell i el seu funcionament, i sobretot té la capacitat d'apropar-se i fer que, aquests continguts que generen un cert respecte, s'entenguin i, a més, siguin utilitzats sense pors i pel bé comú en les comunitats educatives.

El seu treball el realitza juntament amb els doctors Catalán, Casaprima i Ferrer, i tots quatre integren l'equip del "Instituto Médico de Desarrollo Infantil" de Barcelona. Darrere de vint anys de treball conjunt $i$ experiència dedicats al diagnòstic, prevenció i teràpia del desenvolupament infantil, han possibilitat l'elaboració i explicació d'aquests models reactius.

El Dr. Mombiela sempre comença situant el tema en el context de la genètica. En aquest sentit, sosté que tots som fruit de dues parts: $50 \%$ del pare i $50 \%$ de la mare. "La genètica fa meravelles, tenim els ulls del pare, la boca de la mare, l'òs sacre del pare..." Nosaltres el que hem de fer és integrar i això tan sols es pot fer mitjançant les connexions neuronals. Ens regalen el físic, el mental i l'emocional, però no està integrat, és solament un projecte genètic, s'ha de desenvolupar i relacionar amb l'experiència de vida, que és el que ens va succeint des del moment en què som engendrats. De vegades, podem tenir un projecte genètic meravellós però si al moment de néixer tenim problemes d'aquests, inevitablement, afectaran la forma de processar del nostre cervell (Figura 1).

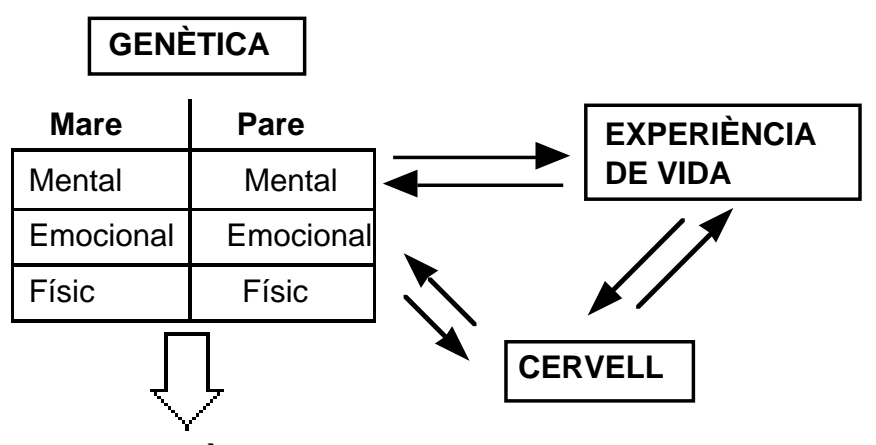

\section{SOBREVIVÈNCIA}

Fig. 1. Integració del projecte genètic amb l'experiència de vida

De la genètica hem de recordar que està dissenyada per a sobreviure, ja que la majoria dels nens que anirem veient en els pròxims anys vénen al món per sobreviure. Això és terrible perquè els mestres s'enfronten a uns nens amb la supervivència en actiu. Tots aquests nens que veiem inquiets, que es belluguen, que no miren, que estan donant la llauna i que no aprenen dels seus errors... vol dir que el seu sistema està saturat. Avui dia s'ha d'insistir en això: si a un nen li costa aprendre dels seus errors, el seu sistema cerebral està saturat, vol dir col-lapsat de quantitat d'impactes que no saps què fer amb ells, l'hem desbordat, avui estem desbordant els cervells. Què passa quan succeeix això? Que es posen en marxa mecanismes de supervivència. D'aquesta manera deixem el projecte genètic en mans d'educadors i mestres. A mesura que aquests van abdicant de les seves funcions, i succeeix quan senten que els pares els pressionen amb les seves demandes, inevitablement molts acaben pensant: " $\mathrm{Va}$, per tres dies que tenim els nens, deixem-los..."

Efectivament, quan permetem que els nens sobrevisquin estem desenvolupant el que el Dr. Mombiela anomena: "Moure's pel plaer i pel desplaer, res més. M'agrada,ho faig; no m'agrada, no ho faig". Avui dia nens de 4 anys ens diuen: "Estic cansat i no tinc ganes 


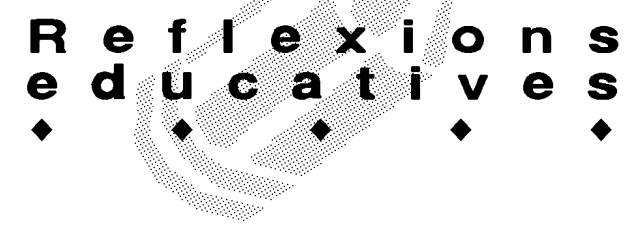

de pintar" I els grans diuen "Oh! Com ho raona, quina barbaritat!"... perquè els nens semblen experts en llenguatge, però darrere d'aquest llenguatge no hi ha res, només un nen de 4 anys.

Habitualment, aquest autor acostuma a explicar en les seves xerrades algunes de les experiències que ha viscut, i comenta: "Fa uns dies, en una reunió, no sé amb qui era, estava jo ja una mica saturat i vaig dir:" A veure, què creiem que és un cervell de 4 anys, l'última innovació tecnològica i l'últim nivell de desenvolupament de l'ésser humà? No! Amb les neurones que funcionen en un cervell de 4 anys podem muntar una calculadora, res més, i ja em direu "parlar amb una calculadora"... Doncs, moltes vegades i situant aquesta expressió dins el context que ens ocupa, parlem amb calculadores que anomenem "Nens". Però els seus cervells estan saturats i aquests sistemes no són operatius. Ara, com que són normals, vas veient que, funcionant pel plaer i el desplaer, sí que funcionen. El problema és que acompleixen les pautes que nosaltres els donem. I aquí és quan s'observa l'art, el desgast i l'estrès que això genera en mestres i educadors. L'explicació que ens dóna és: "Perquè cada dia ens hem de barallar molt més amb unes respostes que són cada vegada més primitives; ja no ens vénen preparats als sistemes, sinó que vénen en condicions de supervivència, plaer i desplaer i entrenats, és a dir, els funciona el sistema i com que els funciona, és normal, i com que és normal: Què m'has de dir tu?". Llavors la distància amb l'adult es trenca, no hi ha distància. "Tu i jo som iguals". I si els mestres continuen fent aquesta acció tan maca de baixar al nivell del nen, s'estan condemnant ja!, perquè oficialment som iguals, així que si baixem és per deixar les coses clares des de dalt. $\mathrm{Ha}$ de quedar molt clar qui és qui ensenya i el que s'ha de fer. Hem de tenir sempre present que els nens vénen preparats per aprendre, però no per ensenyar..."

Hem d'aconseguir la integració del projecte genètic amb l'experiència de vida. D'acord amb això, la genètica i les experiències de vida estan íntimament relacionades, això provoca una interacció, un feed back, un impacte en l'experiència vital, que busca una resposta en la genètica i si aquesta la té, la dóna, sempre lligada a supervivència. L'experiència vital és incorporar-se a l'escola, la genètica no té resposta, llavors què passa? Doncs que necessitem un cervell i aquest es convertirà en un modulador d'aquests dos grans poders, la vida i la vida enllaunada, és a dir, l'ADN. Comprimit, ple d'informació i l'experiència vital, que és la interacció amb el món. Llavors, aquest cervell ha de dir, de mica en mica, a mesura que va madurant, que "en tot el que em pass, abans que tu diguis el que s'ha de fer, jo vull intervenir". Com que aquest cervell és petit, necessita d'educadors i mestres. Nosaltres, els adults, el que fem és tutoritzar "la gravació del disc dur" d'aquest cervell perquè vagi aprenent a modular respostes adaptatives.

\section{Definició, tipologia i aplicació dels models reactius}

Com es pot fer això? Una de les maneres pot ser entenent el que són els models reactius i com podem aplicar-los en la nostra intervenció educativa i de relació amb els altres.

Quan aquests investigadors ens parlen de models reactius, parteixen d'un punt de vista psiconeurofuncional i expliquen que el nostre cervell, amb els dos hemisferis, s'encarrega de controlar tot aquest complex sistema doble i interpreta el món que ens envolta, ens ajuda a comunicar-nos amb ell i a desenvolupar-nos des de les vessants física, mental i afectiva. Així, proposen que són tres les tipologies fonamentals que caracteritzen com és la manera de sentir, de reaccionar i de viure un mateix, i que depenen de quin és l'hemisferi dominant en les funcions sensoemocionals. Així mateix, comenten que no s'ha de confondre amb la dominància cerebral motriu que manifesten les persones dretanes o esquerranes. Aquests models estan relacionats amb la dominància general de les funcions perceptives, emocional $i$ vivencial.

En aquest sentit, són tres els tipus de models reactius que han pogut constatar al llarg de la seva experiència professional en l'estudi de milers de famílies: a) Quan es dóna un predomini de l'hemisferi dret, amb la denominació de model reactiu magnètic. b) Quan el que té un predomini és l'hemisferi esquerre, i el denominen elèctric. c) Quan no té un predomini definit i es poden veure les dues manifestacions anteriors.

En general, quan ens trobem una família de dos fills, generalment, cada fill tindrà una manifestació diferent. Si el més gran té un predomini magnètic, l'altre el tindrà elèctric i viceversa. Si veiem famílies amb tres fills, el tercer tindrà les dues manifestacions. Quan les famílies tenen més de tres fills, es torna a repetir la seqüència $i$ el quart podrà ser 0 magnètic $o$ elèctric.

En què afecta tenir un tipus 0 altre de dominància cerebral? Doncs en la manifestació de tots els àmbits del comportament i vivències emocionals dels nens. D'aquesta manera, les característiques que conformen aquests models les podríem definir de forma sintètica com:

La persona que té un model reactiu magnètic o dominància de l'hemisferi dret és:

Global, intuïtiva, emocional, amb millor memòria a llarg termini, controladora espacial, musical, integra el context, integra la dominància en una globalitat, interpreta el context, creativa, somiadora. 


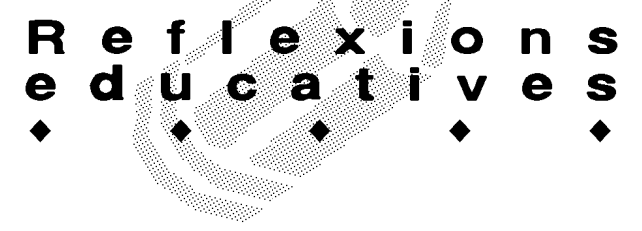

La persona que té un model reactiu elèctric o dominància de l'hemisferi esquerre és:

Lineal, deductiva, racional, amb memòria immediata, controladora temporal, verbal, integra el detall, controla el costat, dominant del cos, descodifica (lletres-nombres), interpreta la realitat, activitat de vigília.

Podríem explicar diferents situacions escolars i de vida per entendre millor aquestes formes de funcionament dels hemisferis.

La manera d'abordar un problema de matemàtiques pot fer-se des de la globalitat o la particularitat. El cervell dret normalment ho fa des de la globalitat; entén, agafa referents externs, mira la cara del pare, del mestre per saber si ho endevina... Aquí cal recordar el saber popular quan diu: "Està pendent del món exterior, veu la vida com una ampolla mig buida". El cervell esquerre la veu mig plena. Normalment es triga trenta anys o més a descobrir que l'ampolla és la mateixa...

L'hemisferi dret agafa el comandament de posar la nota adient a cada sensopercepció que arriba a la seva activitat cortical, li posa un segell i després contrasta amb l'hemisferi esquerre, i després l'hemisferi esquerre ha d'aprendre a col-loquiar amb l'hemisferi dret, però la primera empremta, la primera reacció, la comanda l'hemisferi dret.

Si l'hemisferi dret comanda la interpretació de les sensopercepcions, el que fa el nostre cervell és processar des de la globalitat. Processa des de la síntesi, o processa des de la intemporalitat, de l'emoció o des de la poesia, des de la creativitat o des de la relativitat. És a dir, és un hemisferi que s'anomena magnètic, subtil, és l'amo de les muses, on es vibra, on s'elucubra, es somia. El conte de la lletera està elaborat des de l'hemisferi dret. Qui ho descriu és l'hemisferi esquerre, qui diu "Vigila, perquè si fas el del conte de la lletera et pot passar això". Però muntar-te la vida sobre un estímul, només ho pot fer l'hemisferi dret.

L'hemisferi dret és qui ens fa ocupar-nos i preocuparnos moltíssim per un viatge que haurem de fer dins de sis mesos, però potser no el fem perquè no el tenim confirmat. Ja estic angoixat, perquè he de pujar a l'avió. I estic preocupat de què portaré i estic preocupat de quina temperatura farà. Si he de portar un tipus de roba o una altra, estic ple de preocupacions i encara falten sis mesos per anar-me'n.

L'hemisferi esquerre diu: ¿Està confirmat? No? doncs quan m'ho confirmin ja em preocuparé, ja passaré a l'acció. Així que l'hemisferi dret és un hemisferi contemplatiu, gaudeix contemplant. A vegades veiem el nen que va pel carrer de la mà de la seva mare i que fica el peu on no l'ha de ficar, que xoca contra els retrovisors dels cotxes, que la mare no para de dir: "Però nen, mira on fiques els peus, vols fer el favor de mirar cap endavant?". Aquest nen està comandat per l'hemisferi dret. Respecte a l'hemisferi esquerre només funciona perquè està mirant i diu: "Allà, allà" perquè ha vist una casa de joguines ". Llavors, és el que l'interessa, però quan no l'interessa és ¡No, No, No!, Sí. Així, aquell nen a qui vosaltres expliqueu el que ha de fer i que veieu que és aquí, que és allà, que no és on ha d'estar... en aquests moments és operatiu de forma predominant l'hemisferi dret.

El nen que està esperant que diguem: "Ja podeu començar a escriure o a pintar", ja té el llapis preparat, aquest està operatiu des de l'hemisferi esquerre. Tenim l'experiència de cada dia i és extraordinària.

Quan l'acció és comandada des de l'hemisferi dret, d'una forma molt resumida també diem que és un processador en paral.lel. Vol dir que per anar d'A a B utilitza un circuit on li surten "pedres" en la recerca del que desitja. Així que si vols anar d'A a B, però entremig

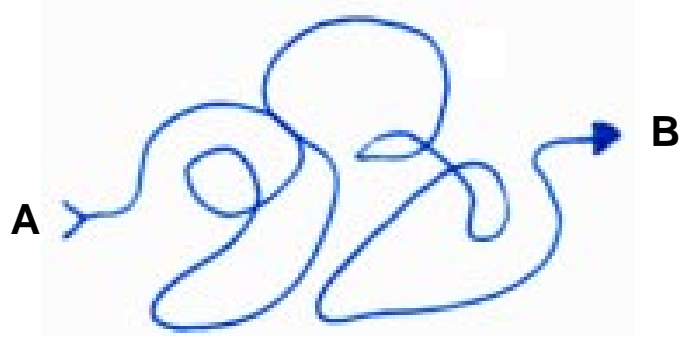

trobes un botó, et distreus, perquè l'altre ha esternudat, perquè li ha caigut un llapis, perquè li pica la cama, perquè ara recordo que tu em vas dir que no seríem amics, i li dius: "X, pots portar el pot dels colors?". I en el moment que li dius, ja li dius una mica enèrgic "Vols fer el favor de portar...!" Nosaltres mobilitzem l'adrenalina d'altres igual que la d'ells mobilitza la nostra. Bé, un procés en paral.lel; hem d' imaginar una xarxa tridimensional de neurones i totes en actiu. Jo vull anar d'A a B i no és recte, començo a connectar, així que dic: "Pintem la poma que teniu aquí davant de color vermell" i ell diu: "Aquesta poma pot tenir un cuc?" Li diem: "Hi veus un cuc tu?". "No hi ha cuc". Diu una altra vegada: "Però podria tenir-lo, ¿no?". Li diem: "Sí, però pinta la poma d'una vegada". És el mateix que dir: "Això (1) és un u?" Sí, "I això $\sqrt{ }$ ?". "També és un u, fent el pi".

$\mathrm{Si}$ recordeu l'època en què nosaltres anàvem a l'escola, hi havia dies que estudiàvem amb l'hemisferi dret i d'altres que ho fèiem amb l'hemisferi esquerre. Llavors quan ho fèiem més amb l'hemisferi esquerre, doncs alguns de nosaltres, quan quedaven pocs dies per a fer l'examen, vèiem un totxo gruixut $i$ ens hi jugàvem molt. Faltaven tres dies i calia un esforç de 


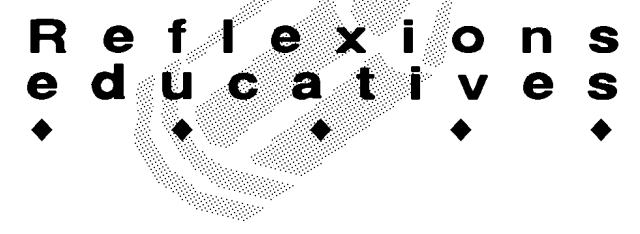

colzes. Ens trucàvem i dèiem: "No, no puc." Els altres deien: "Com has canviat!". I reies: "Jo, canviar? És que tinc tres dies per estudiar, perquè tinc un examen de nassos i m'hi estic jugant moltíssim" I funcionava l'hemisferi esquerre i pensaves: "Ondia, que bé m'ha anat, no? La propera vegada faré el mateix, però amb més temps". I no ho feia. Costa molt aprendre aquestes coses quan la resta del curs has viscut des de l'hemisferi dret. Així que des de l'hemisferi dret dius: "Bé, encara queden quasi 20 dies". Llavors agafes el llibre, t'ho programes, ho llegeixes, no t'assabentes de res, tornes a llegir, no t'assabentes de res, falta què? Adrenalina. Falta aquest motor d'adrenalina que actives 0 al néixer ja el tens activat. Llavors en el moment que tu li dius al cervell que has d'estudiar, l'adrenalina, pum! surt al torrent circulatori, però des de l'hemisferi dret és "seria bo que estudiïs". I quan el cervell sent això diu "para!, no segreguis adrenalina". Que diu que li sembla que vol estudiar, és a dir, "si vull, ja ho faré, tinc temps", amb tot això les suprarenals no es mouen. Ara, quan de sobte topes, s'activa l'adrenalina. D'aquí recordarem nombroses anècdotes de pares que diuen: "Aquest nen és insuportable, no fa cas, li parles, i ell tomba i gira. Em va posar...!, li vaig plantar una bufa... «Mano de santo». Durant tres dies, molt ferms". Fixeu-vos en la intensitat de la bufa... Imagineu-vos per activar les suprarenals, l'hemisferi dret i des d'aquest hemisferi posar-ho en el seu lloc. I ara, avui dia, això se sent moltes més vegades, perquè els nens estan jugant molt amb aquesta adrenalina i sense escoltar. Com que no escolten, es deixen portar pels seus plaers i desplaers: "Si no m'agrada, no ho faig; si m'agrada, ho faig" i d'aquesta manera es van escalfant les neurones de mala manera. Quan la informació es processa predominantment des de l'hemisferi esquerre i des d'aquest passa a contrastar-se amb l'hemisferi dret, la vida s'entén d'una manera molt més lineal i pràctica. Per anar d' $A$ a $B$ utilitzem la linealitat $(A \rightarrow B)$.

\section{Què ens trobem a les classes}

D'aquesta manera, a l'escola podem dividir la classe en nens lineals, en nens en paral.lel i després està la mitjana, els que funcionen de les dues maneres. De tant en tant es distreuen i els mires i els dius: " $\mathrm{Va}$, nen, que et quedaràs sense pati" i buixim! Es posa en marxa I'hemisferi esquerre, o bé "per anar al pati has de fer això" i buixim!, ho fa. Al nen d'hemisferi dret li dius: "Mira, que si no acabes a l'hora del pati et quedaràs sense jugar i hauràs de fer la fitxa" i et mira així, com dient: "El pati em sona, eh!, la fitxa també, però no entenc de què va la pel-lícula. Si jo estic treballant..." Es perd aquesta informació. En canvi, al nen predominant en els dos hemisferis li dónes un copet i arranca. Això és una mitjana, després hi ha l'extrem quan vas una mica fora de joc i l'altre extrem no et deixa viure. Per exemple: molts nens amb predominància d'hemisferi esquerre quan els dius que pintin una poma els has de donar tres pomes perquè pintin. N'hi ha que pinten la primera, a tota castanya, i diuen: "Ja he acabat", i la resta encara està dient: "Ah! Que bé, hem de pintar una poma". I el nen de l'hemisferi esquerre ja està pintant la segona, amb cuc, i té, ara pinta una pera. Fins que n'aprenen, i llavors es dediquen a xerrar, quan descobreixen que això funciona bé i diuen: "Com que ja he acabat, em donen una altra fitxa", llavors ja no pinten tan ràpid. El primer dia estan orgullosos, però un dia el cervell els diu: "Sembla que estiguis fent el babau" Llavors van pintant $i$ van observant l'entorn, i com que els altres no han acabat ells fan un stop i comencen a molestar, després tornen a pintar i així van fent.

Des del punt de vista occidental, la linealitat és més productiva. La linealitat és més propera a allò més racional, és tangible, al lineal, al pràctic, a l'anàlisi. Llavors quan la vida s'interpreta d'aquesta manera és molt més productiva des del punt de vista occidental, que no vol dir que sigui el millor, sinó que des del punt de vista occidental coincideix molt amb aquest tarannà, amb les demandes de l'entorn. Així que amb aquest sistema de funcionament es tenen més possibilitats d'èxit.

Normalment, nosaltres com a adults, també tenim una dominància hemisfèrica determinada, i en la nostra interacció a classe i a la vida quotidiana ens trobem amb persones amb les quals sintonitzem més o menys. A mesura que ens anem fent grans, hauríem d'aconseguir la integració interhemisfèrica, és a dir, tenir un desenvolupament en el qual es doni la complementarietat entre ambdós hemisferis. Que no és sinó el que ens equilibra en les nostres funcions perceptives, emocionals i vivencials $i$ ens permet completar-nos amb els altres.

\section{Bibliografia consultada}

FERRÉ, J. Los trastornos de la atención y la hiperactividad. Diagnóstico y tratamiento neurofuncional y causal. Ediciones Lebón. Barcelona. 1999.

VVAA. El desarrollo de la lateralidad. Edit. Instituto Médico del Desarrollo Infantil. Barcelona. 1996. 